\title{
Performance Study on the Bonding Mortar for Prefabricated Light Weight AAC Composite Board
}

\author{
Ye Zhang, Ji Xiu Zhang, Sai Hong Duan, Ji Kang Liu, Yuan Chao Miao \\ National Key Laboratory of Solid Waste Resource Utilization and Energy-saving Building Materials \\ Beijing Building Materials Academy of Sciences Research, Beijing, 100041, China
}

\begin{abstract}
In this paper, the tensile bond performance of different bonding mortars for lightweight composite boards of autoclaved aerated concrete which can be prefabricated in factory is studied. The performance requirements of bonding mortar for the composite boards are proposed. The research methods refer to relevant Chinese standards. The results indicate that the tensile bond strength of bonding mortars for the lightweight aerated concrete substrates varies with the curing age increasing. The special bonding mortar for prefabricated composite board of light weight aerated concrete should have the characteristic of early and relatively high strength in a short curing age. And its early tensile bond strength should not be less than $0.35 \mathrm{MPa}$ in 3 hours.
\end{abstract}

\section{Introduction}

With the rapid development of urbanization, the industrialization of buildings characterized by design standardization, factory manufacturing, and construction assembly has become an inevitable trend of the times. In prefabricated buildings, the prefabrication of multifunctional exterior walls which has the characteristics of energy-saving, light weight and beautiful facade is a key indicator and important link for assessing the level of industrialization of buildings [1]. Lightweight autoclaved aerated concrete (AAC) composite wallboard is a new type of assembled exterior wallboard. This composite board uses a lightweight AAC board as the core material and high density calcium silicate slab on both sides of the core material. The key link of this kind of sandwich-type composite board is the cohesive performance of its matching bonding mortar. Therefore, the characteristics of special mortar for the light weight AAC composite boards are particularly important ${ }^{[2]}$. At present, the research of AAC matching mortar is mainly focused on AAC block, such as masonry mortar and plastering mortar ${ }^{[3-5]}$. There are few studies on the bonding mortar of AAC composite boards ${ }^{[6-7]}$.

The commonly used binders on the market are divided into two types: inorganic bonding mortars and organic adhesives. Considering the compatibility and durability of the materials, the focus in this paper is the proper inorganic binder for the prefabricated composite board. Based on the bonding performance characteristics of four inorganic bonding mortars, the matching tensile bond strength range of the bonding mortar between light weight $\mathrm{AAC}$ and the side layers are analyzed.

\section{Experimental}

\subsection{Materials}

Table 1 The properties of AAC board

\begin{tabular}{ccccc}
\hline $\begin{array}{c}\text { Kind of AAC } \\
\text { board }\end{array}$ & $\begin{array}{c}\text { Moisture content } \\
[\%)]\end{array}$ & $\begin{array}{c}\text { Dry weight } \\
{\left[\mathrm{kg} / \mathrm{m}^{3}\right]}\end{array}$ & $\begin{array}{c}\text { Controlled weight } \\
\text { range }\left[\mathrm{kg} / \mathrm{m}^{3}\right]\end{array}$ & $\begin{array}{c}\text { Compressive } \\
\text { strength }[\mathrm{MPa}]\end{array}$ \\
\hline 03 & 27.3 & 296 & $280-325$ & $1.0-1.5$ \\
\hline 04 & 25.8 & 390 & $380-425$ & $2.0-2.5$ \\
\hline Target board & 23.6 & 356 & $330-360$ & $1.5-2.0$ \\
\hline
\end{tabular}

As mentioned above, the AAC composite board is a sandwich-type board and light weight AAC is used as core board. The calcium silicate slab is compounded on both sides of the center board by bonding mortar. Three different weight ranges of light weight AAC boards are

\footnotetext{
*Corresponding author: yezh_001@126.com
} 
chosen. Two of them are commonly produced standard bulk density board (B03, B04) and one is non-standard (target board). The properties of AAC boards and calcium silicate slabs are outlined in Table 1 and Table 2 respectively. The experimental mortar samples A-D are commercially available bonding mortars.

Table 2 The properties of calcium silicate slab

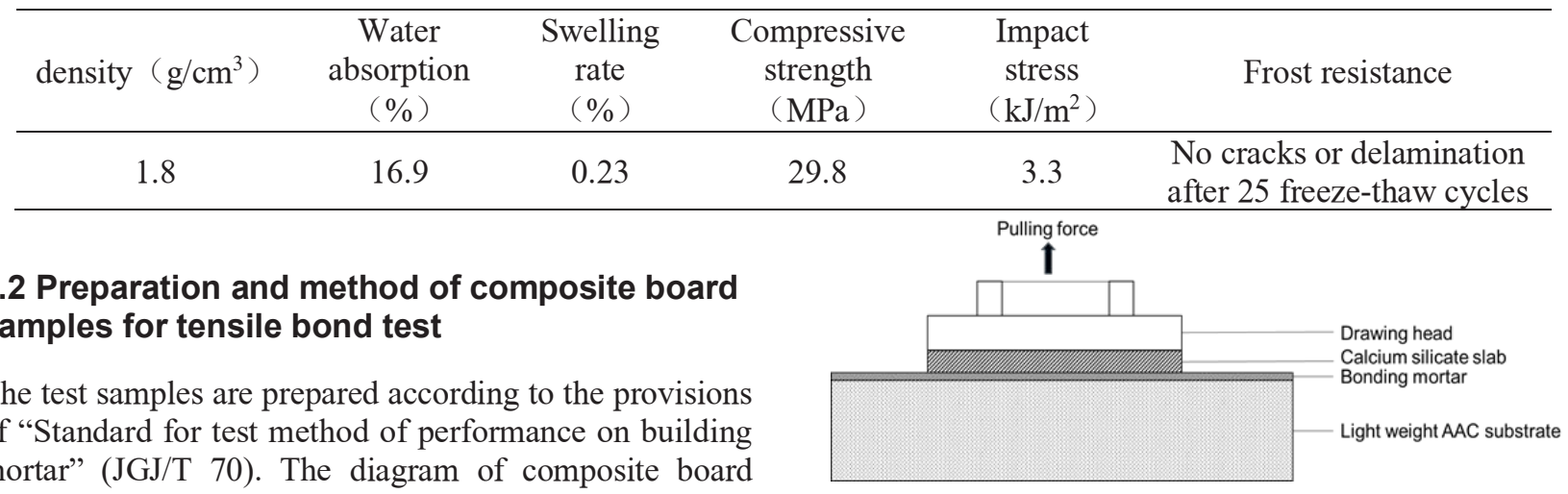
sample is shown in Fig.1.

Fig.1. The diagram of AAC composite board sample

\section{Result and discussion}

\subsection{The tensile bond strength of different binders}

Table 3 The tensile strength of different binders with light weight AAC

\begin{tabular}{ccccccccc}
\hline \multirow{2}{*}{ Binder } & \multicolumn{3}{c}{ The tensile strength with AAC 03 [MPa] } & \multicolumn{5}{c}{ The tensile strength with AAC 04 [MPa] } \\
\cline { 2 - 10 } & $3 \mathrm{~d}$ & $7 \mathrm{~d}$ & $14 \mathrm{~d}$ & $28 \mathrm{~d}$ & $3 \mathrm{~d}$ & $7 \mathrm{~d}$ & $14 \mathrm{~d}$ & $28 \mathrm{~d}$ \\
\hline $\mathrm{A}$ & 0.36 & 0.30 & 0.36 & 0.37 & 0.32 & 0.35 & 0.39 & 0.37 \\
\hline $\mathrm{B}$ & 0.40 & 0.40 & 0.41 & 0.36 & 0.44 & 0.41 & 0.46 & 0.57 \\
\hline $\mathrm{C}$ & 0.28 & 0.32 & 0.32 & 0.30 & 0.33 & 0.39 & 0.43 & 0.42 \\
\hline $\mathrm{D}$ & 0.32 & 0.41 & 0.40 & 0.39 & 0.39 & 0.42 & 0.46 & 0.55 \\
\hline
\end{tabular}

All the test samples based on B03 and B04 AAC substrates are cured after 3 days, 7 days, 14 days, and 28 days, respectively. The tensile bond strength data is shown in Table 3. The appearance of the tensile fracture surface between bonding mortar A-D and light AAC at different ages is shown in Fig.2 and Fig.3. Different binders have different bonding strength to the substrate, and the appearance of fracture with the substrate also varies with the increasing of age.

Binder A: From Fig. 2, at the age of $3 d, 7 d$ and $14 d$, no matter which substrate, the fracture layer in the tensile bond test appears in the mortar itself. It indicated the early-age cohesion of binder A cannot resist the pulling force. Until at the age of 28 days, the site of the fracture appears only in B03 substrate and its 28-day age strength is $0.37 \mathrm{MPa}$. But the fracture surface never appeared inside the B04 substrate.

Binder B: As shown in Fig.2, at the age of 3d, most of the points in the B03 AAC substrate are broken, but B04 had only few broken sites. After 14 days of curing, all the pull-out fracture layers are B03 and B04 AAC substrates.
At the age of $28 \mathrm{~d}$, all the pull-out fracture layers are still aerated layers but with deep pits. The 28-day bonding strength of binder $\mathrm{B}$ for $03 \mathrm{AAC}$ and $04 \mathrm{AAC}$ are $0.36 \mathrm{MPa}$ and $0.57 \mathrm{MPa}$ respectively.

Binder C: As shown in Fig.3, at the age of 7d, the B03 AAC substrate is broken and B04 has a few broken points. The bonding strength for 03AAC and 04AAC are $0.32 \mathrm{MPa}$ and $0.39 \mathrm{MPa}$, respectively. After 14 days of curing, all the pull-out sites are broken and the fracture layers are AAC substrates themselves. The bonding strength for $03 \mathrm{AAC}$ and $04 \mathrm{AAC}$ are $0.32 \mathrm{MPa}$ and $0.43 \mathrm{MPa}$, respectively. At the age of $28 \mathrm{~d}$, the bonding strength of binder $\mathrm{C}$ for $03 \mathrm{AAC}$ and $04 \mathrm{AAC}$ are $0.30 \mathrm{MPa}$ and $0.42 \mathrm{MPa}$ respectively.

Binder D: at the age of $14 \mathrm{~d}$, the B03 AAC substrate is broken and B04 AAC substrate has no broken points. After 28 days of curing, 50\% of points have been damaged in B04 substrate. The bonding strength of binder D for 03 $\mathrm{AAC}$ and $04 \mathrm{AAC}$ are $0.39 \mathrm{MPa}$ and $0.55 \mathrm{MPa}$ respectively. 

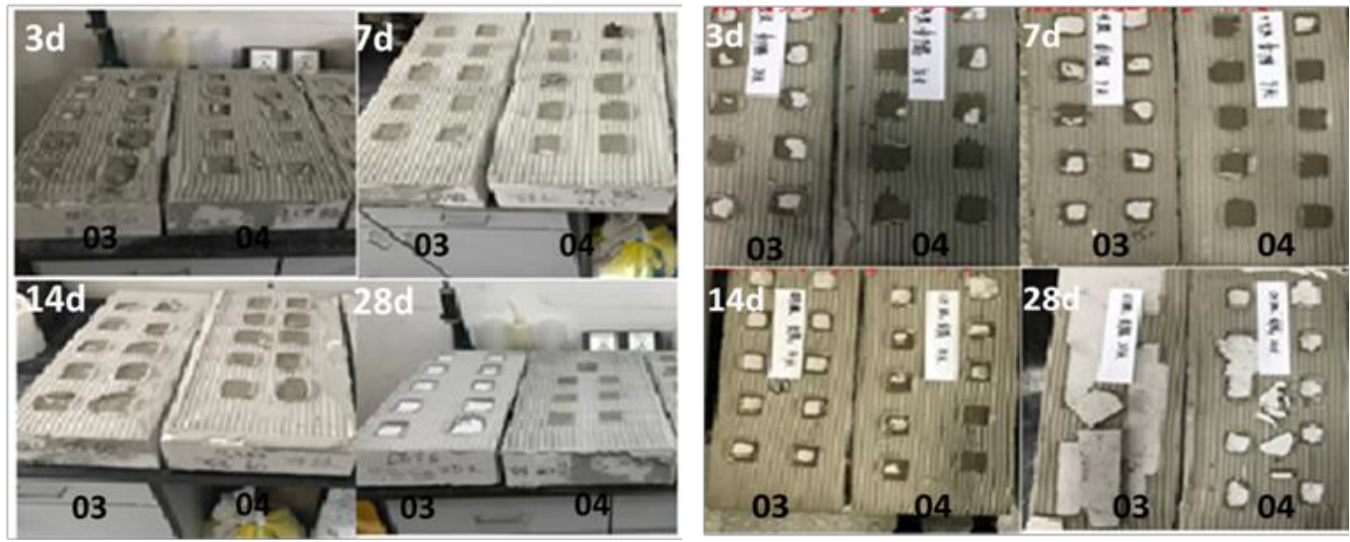

Fig.2 The tensile fracture surface appearance of bonding mortar A (left) and B (right) with light AAC at different ages
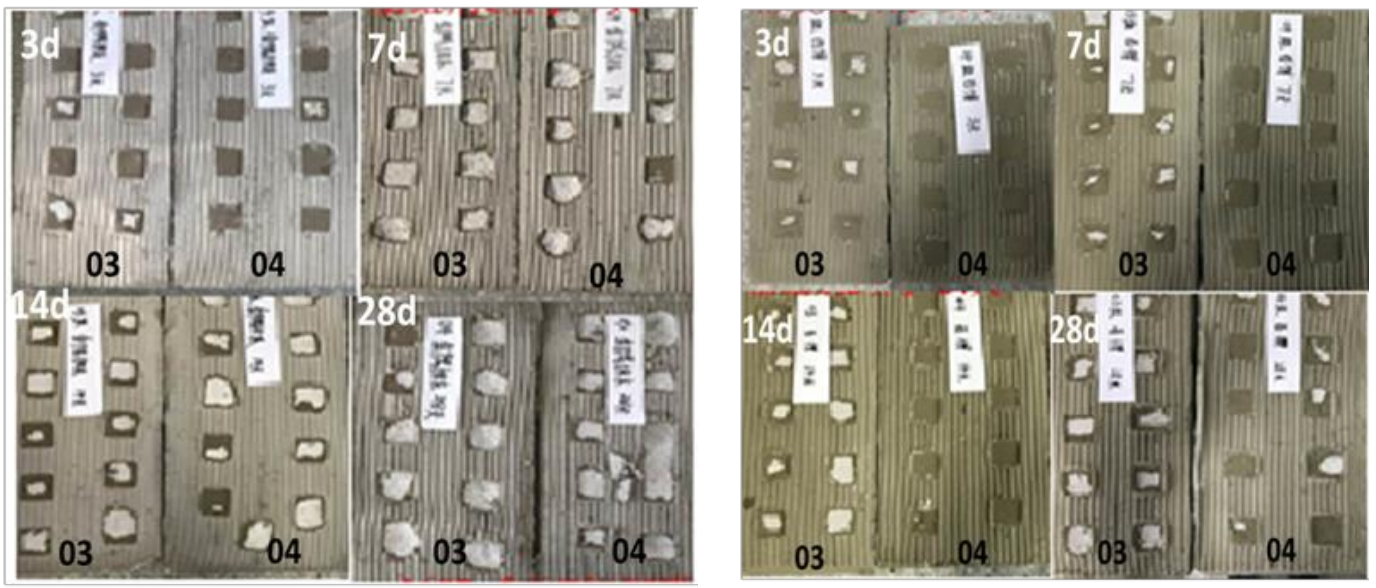

Fig.3 The tensile fracture surface appearance of bonding mortar C (left) and D (right) with light AAC at different ages

\subsection{The tensile bond strength requirement for the special bonding mortar used in light weight AAC composite boards}

In the process of tensile bond tests, there is no phenomenon of calcium silicate slab peeling off from the surface of the bonding mortars. It indicates the bonding mortars A-D have good adhesion with the calcium silicate slab. However, the bonding strength of different binders to the lightweight AAC (B03-B04) substrates varies with the curing age. With the increasing of age, the bonding effect is different. And due to the uneven strength of the AAC substrate, some data of the tensile bond strength fluctuates. From the combination results of tensile bond test values and fracture morphology, the proper tensile bond strength of matching bonding mortars for B03 AAC and B04 AAC substrate are not lower than $0.3 \mathrm{MPa}$ and $0.4 \mathrm{MPa}$, respectively.

Since the prefabricated lightweight AAC composite board needs to be mechanically compounded in the factory, for the special bonding mortar, it is necessary to achieve higher strength in a shorter time to ensure the composite quality and production rhythm of the composite boards. Because the pressing time of the composite board is 4 hours, its matching bonding mortar is best to reach $0.35 \mathrm{MPa}$ in 4 hours. As shown in Fig. 4 , the special bonding mortar used in light weight AAC composite boards are cured for 1-72 hours and then subjected to pull-out tests, and the failure surfaces are all AAC substrates layers. It can be seen in Fig. 5 that the tensile bond strength reaches $0.37-0.38 \mathrm{MPa}$ in 3-4 hours, and after 8 hours, it reaches $0.47 \mathrm{MPa}$. And the fracture surfaces after drawing are all target AAC board Substrates which has the bulk density range of $330-360 \mathrm{~kg} / \mathrm{m}^{3}$. The relatively high early-strength is favorable for the handling and stacking of the composite boards and avoiding damage. The results show that the special bonding mortar can achieve better bonding performance with target AAC composite boards and calcium silicate slabs in a short time which is in line with the expected research and development goals.

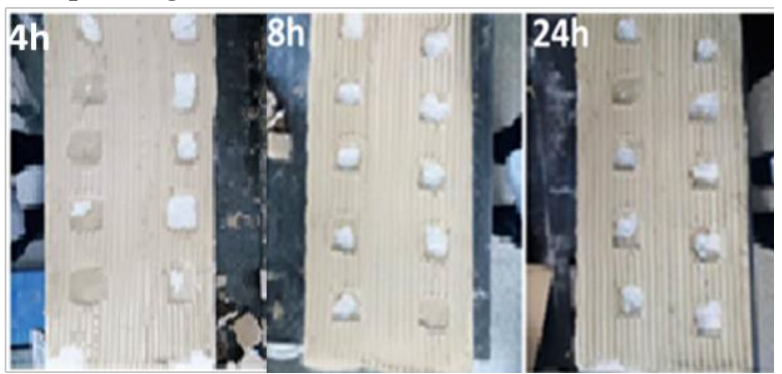

Fig.4. The tensile fracture surface appearance of special bonding mortar with light $\mathrm{AAC}$ in a short period of curing time 


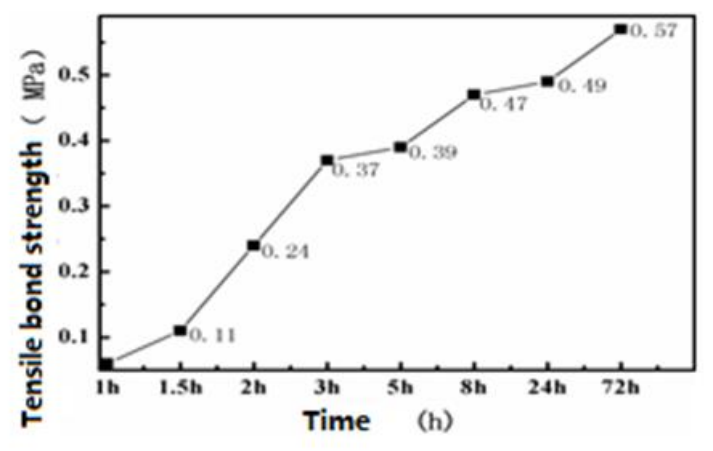

Fig 5 The tensile bond strength change curve of special bonding mortar at different ages

\section{Conclusions}

In this paper, the lightweight AAC composite board that can be prefabricated in the factory is taken as the research object, and the required binder properties are explored. Based on the study of the bonding performance of ordinary bonding mortars for composite boards, the performance requirements for the special bonding mortar used in the lightweight AAC composite board prefabrication are proposed. The test results show that the tensile strength of bonding mortars for the lightweight aerated concrete substrates varies with the curing age increasing and the kind of the AAC substrates. The proper tensile bond strength of bonding mortars for B03 AAC and B04 AAC substrate are not lower than $0.3 \mathrm{MPa}$ and $0.4 \mathrm{MPa}$, respectively. The special bonding mortar for prefabricated composite board of light weight AAC (target board) has good bonding ability with AAC substrate and calcium silicate slab. After 3-4 hours of curing, the tensile bond strength reached $0.37 \mathrm{MPa}$, and it reached $0.47 \mathrm{MPa}$ in 8 hours, and the fracture surfaces after drawing are all AAC substrates themselves. The special bonding mortar for developed light-weight aerated concrete composite exterior wall board has the characteristics of proper early strength and high bonding strength, which lay a technical foundation for the prefabrication of the factory-made composite board.

\section{Acknowledgements}

This work was financially supported by Beijing Special Fund for New Wall Materials Program.

\section{References}

1. Xinxiang Wang, Jian-xin Li. Development Status and Trend of Energy-saving Decoration Integrated Assembled Exterior Wall Panel. Construction Science and Technology, 2014 (8):55.

2. Tongzeng Gu. Reconsider on Single Thermal Insulation Energy Efficiency Wall System of Aerated Concrete. Construction Conserves Energy, 2008 (36): 31.

3. Shenyang He. Thin-layer Mortar Construction of Aerated Concrete Masonry. Block brick tile, 2019 (11): 117.

4. Juhong Han, Shiwei Gao, Suping Bi. Performance of supporting mortar for autoclaved aerated concrete block. Concrete, 2011 (7): 109.

5. Zhaoming Huang, Yufei Yuan, Ziyun Wen. Study on high performance thin layer dry powder mortar. Wall materials innovation \& energy saving in buildings, 2011(6): 57.

6. Haifeng Huang, Kai Shu, Danmei Ye. Development of Special Mortar for Autoclaved Aerated Concrete Products and Application Prospects of its Dry Construction. Wall materials innovation \& energy saving in buildings, 2019 (6): 17.

7. Ge Yang. Development of Autoclaved Aerated Concrete Self-insulation System. Henan Building Material, 2013 (5): 198. 